\title{
Temperature and microbial changes of corn silage during aerobic exposure
}

\author{
Seong Shin Lee, ${ }^{1, a}$ Hyuk Jun Lee ${ }^{1, a}$, Dimas Hand Vidya Paradhipta ${ }^{1,2}$, Young Ho Joo ${ }^{1}$, \\ Sang Bum Kim ${ }^{3}$, Dong Hyeon $\mathrm{Kim}^{3,4}$, and Sam Churl Kim ${ }^{1,4, *}$
}

\footnotetext{
* Corresponding Author: Sam Churl Kim Tel: +82-55-772-1947, Fax: +82-55-772-1949, E-mail: kimsc@gnu.ac.kr
}

${ }^{1}$ Division of Applied Life Science (BK21Plus, Institute of Agriculture \& Life Sciences), Gyeongsang National University, Jinju 52828, Korea

2 Faculty of Animal Science, Universitas Gadjah Mada, Yogyakarta, 55281, Indonesia

${ }^{3}$ Dairy Science Division, National Institute of Animal Science, RDA, Cheonan 31000, Korea

${ }^{4}$ Department of Animal Sciences, IFAS, University of Florida, Gainesville, FL 32608, USA

a These authors contributed equally to this work.

ORCID

Seong Shin Lee

https://orcid.org/0000-0002-4872-3705

Hyuk Jun Lee

https://orcid.org/0000-0003-4766-6742

Dimas Hand Vidya Paradhipta

https://orcid.org/0000-0001-7233-469X

Young Ho JoO

https://orcid.org/0000-0002-3041-623X

Sang Bum Kim

https://orcid.org/0000-0002-8187-4134

Dong Hyeon Kim

https://orcid.org/0000-0003-0756-8419

Sam Churl Kim

https://orcid.org/0000-0003-3105-0118

Submitted Jul 27, 2018; Revised Sept 4, 2018;

Accepted Nov 5, 2018
Objective: This study was conducted to estimate the temperature and microbial changes of corn silages during aerobic exposure.

Methods: Kwangpyeongok (KW) and Pioneer 1543 (PI) corn hybrids were harvested at 29.7\% of dry matter and chopped to 3 to $5 \mathrm{~cm}$ lengths. Homo (Lactobacillus plantarum; LP) or hetero (Lactobacillus buchneri; LB) fermentative inoculants at $1.2 \times 10^{5}$ colony forming unit/g of fresh forage was applied to the chopped corn forage which was then ensiled in quadruplicate with a $2 \times 2$ (hybrid $\times$ inoculant) treatment arrangement for 100 days. After the silo was opened, silage was sub-sampled for analysis of chemical compositions, in vitro digestibility, and fermentation indices. The fresh silage was continued to determine aerobic exposure qualities by recorded temperature and microbial changes.

Results: The KW silages had higher $(\mathrm{p}<0.01)$ in vitro digestibilities of dry matter and neutral detergent fiber than those of PI silages. Silages applied with LB had higher $(p<0.001)$ acetate concentration, but lower $(\mathrm{p}<0.01)$ lactate concentration and lactate to acetate ratio than those of LP silages. The interaction effect among hybrid and inoculant was detected in acetate production $(\mathrm{p}=0.008)$, aerobic stability $(\mathrm{p}=0.006)$, and lactic acid bacteria count $(\mathrm{p}=0.048)$. The yeast was lower $(p=0.018)$ in LB silages than that in LP silages. During the aerobic exposure, PI silages showed higher $(\mathrm{p}<0.05)$ temperature and mold than KW silages, while LP silages had higher $(\mathrm{p}<0.05)$ lactic acid bacteria and yeast than LB silages.

Conclusion: The results indicated that the changes of silage temperature during aerobic exposure seems mainly affected by mold growth, while applied LB only enhanced aerobic stability of PI silages.

Keywords: Aerobic Stability; Corn Silage; Fermentation Indices; Inoculant; Silage Temperature

\section{INTRODUCTION}

Corn silage is a major source of forage for ruminants, which provides a higher energy level compared to other forages. Combining corn silage with protein sources has been applied to supply the nutritional requirement of beef or dairy cattle [1]. High concentration of water soluble carbohydrate (WSC) in corn forage causes higher potential of becoming overgrown by toxigenic fungi such as Fusarium, Pencillium, and Aspergillus genera [2,3] after fermentation compared to the other forages. Aerobic stability is an important factor to ensure corn silage quality and provide a good preserved nutrient with low amount of mold spores and toxicogenic compounds [4]. In addition, the undesirable spores have adverse effects on animal health and reduce their performance [5]. After opened the silo, yeast and mold will grow by degrading the nutrient and organic acids of silage that decrease aerobic stability [4]. The low aerobic stability decreases the utilization and nutritional value of corn silage [6].

In general, the aerobic stability of silage is usually calculated by the changes of temperature 
[7] or $\mathrm{CO}_{2}$ emission [8]. The temperature and $\mathrm{CO}_{2}$ levels of silage will increase during aerobic deterioration [4]. However, both these measurements do not always indicate clearly the growth of undesirable microorganisms during aerobic exposure. Consequently, the changes of temperature and microbes during aerobic exposure might be a direct indicator to determine the shelf life of corn silage.

Nowadays, varieties of hybrids have been developed to increase the productivity, quality, and efficiency of corn plants. In South Korea, Kwangpyeongok (KW) and Pioneer 1543 (PI) are the most widely planted corn hybrids in ruminant industry to supply feed forages. The KW hybrid is more adaptive resulting in higher dry matter (DM) yield and resistance to blackstreaked dwarf virus [9], while PI hybrid produces higher grain yield [10]. The previous studies reported that application of hybrid had effect on fermentation quality and aerobic stability of corn silage [11-13]. On the other side, it is well known that applying a lactic acid bacteria (LAB) can increase fermentation and aerobic stability of silage. A homo fermentative LAB in silage enhances the fermentation quality by increasing lactate production [14], while a hetero fermentative LAB enhances the aerobic stability by increasing acetate production $[15,16]$. An interaction between hybrid and inoculant can be occurr and influence the silage quality [17].

Information of microbial growth such as LAB, yeast, and mold during aerobic exposure is limited regarding the silage temperature changes. In fact, this information could show the contribution of these microbes to an increase of silage temperature and facilitate an estimate shelf life of silage once the silo is opened. Therefore, this study was conducted to estimate aerobic stability of corn silage by observing temperature and microbial changes during aerobic exposure with two different hybrids and inoculants.

\section{MATERIALS AND METHODS}

\section{Silage production}

Two corn hybrids, KW (National Crop Experiment Station, Suwon, Korea) and PI (DuPont Pioneer, Aurelia, USA), were grown at the animal research unit, Gyeongsang National University, Jinju, Korea, and then harvested at $29.7 \%$ of DM. Both corn hybrids were chopped by conventional forage harvester (BHC-90, BUHEUNG Machinery Ltd., Jinju, Korea) into 3-5 $\mathrm{cm}$ lengths. After that, KW and PI forages were inoculated with bacterial inoculants: Lactobacillus plantarum (L. plantarum, LP; CMbio, Anseong, Korea) and Lactobacillus buchneri KACC12416 (L. buchneri, LB; Korean Culture Center of Microorganism, Seoul, Korea), respectively. Application rate of LP and $\mathrm{LB}$ were at $1.2 \times 10^{5} \mathrm{cfu} / \mathrm{g}$ of fresh forage as the recommend level for silage inoculant [7]. All treatments were ensiled into $20 \mathrm{~L}$ mini silos $(8 \mathrm{~kg})$ in quadruplicate for 100 days. After ensiled for 100 days, a total 16 silos were opened, and the silages were sub-sampled for chemical compositions, fermentation indices, microbial counts, and aerobic stability.

\section{Chemical compositions}

Forages and silages (500 g, respectively) were subsampled for chemical compositions, and dried at $55^{\circ} \mathrm{C}$ for $48 \mathrm{~h}$, and ground to pass $1 \mathrm{~mm}$ screen of grinder (Cutting Mill, SHINMYUNG ELECTRIC Co., Ltd, Gimpo, Korea). The DM was determined in dry oven at $105^{\circ} \mathrm{C}$ for $24 \mathrm{~h}$, and crude ash was measured with a muffle furnace at $550^{\circ} \mathrm{C}$ for $5 \mathrm{~h}$. Crude protein (CP) and ether extract (EE) were determined by the producers of Kjeldahl using N analyzer (B-324, 412, 435 and 719 S Titrino, BUCHI, Essen, Germany) and Soxhlet [18], respectively. Neutral detergent fiber (NDF) and acid detergent fiber (ADF) were analysed by using Ankom ${ }^{200}$ fiber analyzer (Ankom Technology, Macedon, NY, USA) [19].

Animal care procedure for cannulated Hanwoo heifers in the present study was approved by animal ethical committee of Gyeongsang National University, Jinju, South Korea. Rumen fluid was collected before morning feeding from two cannulated Hanwoo heifers fed rice straw and commercial concentrate at 8:2 ratio. The collected rumen fluid was composited and filtered via 2 layers of cheesecloth. Forage and silage samples were incubated in mixture of rumen fluid and buffer solution at 1:2 ratio to determine in vitro digestibility of DM (IVDMD) and NDF (IVNDFD) through an Ankom Daisy (Ankom Technology, USA) [20].

\section{Fermentation indices}

Twenty grams of silage were mixed along with $200 \mathrm{~mL}$ of distilled water to make silage extraction for $\mathrm{pH}$, ammonia- $\mathrm{N}$, lactate, volatile fatty acid (VFA), and microbial counts. The $\mathrm{pH}$ was measured with electric $\mathrm{pH}$ meter (SevenEasy, Mettler Toledo, Greifensee, Switzerland) and ammonia-N was analyzed by colorimetry [21]. For lactate and VFA analyses, the silage extraction was centrifuged at 5,645 $\times g$ for $15 \mathrm{~min}$ and collected the supernatant. The concentrations of lactate and VFA were determined using HPLC (L-2200, Hitachi, Tokyo, Japan) fitted with a UV detector (L-2400; Hitachi, Japan) and a column (Metacarb 87H; Varian, Palo Alto, CA, USA) described by Muck and Dickerson method [22].

\section{Microbial counts and aerobic stability}

Fresh silage extraction (first dilution) was continued in several dilutions $\left(10^{-5}\right.$ to $\left.10^{-7}\right)$ to determine $\mathrm{LAB}$, yeast, and mold counts. The lactobacilli MRS agar medium (MRS; Difco, Detroit, MI, USA) was used for the isolation and count of LAB, and potato dextrose agar medium (PDA; Difco, USA) was used for the isolation and counts of yeast and mold. The lactobacilli MRS agar medium was placed in a $\mathrm{CO}_{2}$ incubator (Thermo Scientific, Waltham, MA, USA) at $30^{\circ} \mathrm{C}$ for $48 \mathrm{~h}$ and PDA medium was incubated at $28^{\circ} \mathrm{C}$ for $72 \mathrm{~h}$ in aerobic incubator 
(Johnsam Corporation, Boocheon, Korea). Visible colonies were counted from the agar medium at appropriate dilutions and the number of colony forming units (cfu) was expressed per gram of silage. The aerobic stability was determined by transferring silage $(2 \mathrm{~kg})$ into open-top polyethylene containers. Three thermocouple wires were placed to the center of silage and connected to data loggers (TR-60CH, MORGAN, Hong Kong, China) along with a computer that recorded temperature at every $30 \mathrm{~min}$ for $30 \mathrm{~h}$. The silage containers were covered with 2 layers of cheesecloth to prevent drying and contamination by dust. The aerobic stability was measured by the time required to raise the silage temperature $2^{\circ} \mathrm{C}$ above the ambient temperature $\left(20^{\circ} \mathrm{C}\right)$ as suggested by previous study [7]. During 8 days of aerobic exposure, silage from polyethylene containers was sub-sampled (100 g, respectively) in every day to determine the microbial counts. The protocol of microbial counts was same as described before.

\section{Statistical analysis}

This experiment had a completely randomized design with a 2 (hybrid; KW vs PI) $\times 2$ (inoculant; LP vs LB) factorial arrangement of treatments. All data of chemical compositions, fermentation indices, aerobic stability, microbe counts, and temperature of corn silages were analyzed using general linear model procedure of Statistical Analysis System ver. 9.3 [23] and a model containing hybrid, inoculant, and interactions of these terms. Significance difference was declared at $\mathrm{p}<0.05$.

\section{RESULTS}

\section{Chemical composition of corn forage and silage}

The concentrations of DM, CP, NDF, ADF, IVDMD, and IVNDFD of KW forage before ensiling were 29.7\%, 9.65\%, 51.7\%, $28.1 \%, 60.3 \%$, and $44.9 \%$, respectively (Table 1 ). Whereas, the concentrations of DM, CP, NDF, ADF, IVDMD, and IVNDFD of PI forage before ensiling were 29.7\%, 10.4\%, 47.0\%, 23.5\%, $60.6 \%$, and $45.2 \%$, respectively.
Table 1. Chemical compositions and in vitro digestibility of corn forages before ensiling ( $\%$, dry matter)

\begin{tabular}{lcc}
\hline Items & KW & PI \\
\hline Dry matter & 29.7 & 29.7 \\
Crude protein & 9.65 & 10.4 \\
Ether extract & 3.98 & 3.50 \\
Crude ash & 6.10 & 5.87 \\
Neutral detergent fiber & 51.7 & 47.0 \\
Acid detergent fiber & 28.1 & 23.5 \\
In vitro dry matter digestibility & 60.3 & 60.6 \\
In vitro neutral detergent fiber digestibility & 44.9 & 45.2 \\
\hline
\end{tabular}

KW, Kwangpyeongok hybrid; PI, Pioneer 1543 hybrid.

After silo opened, KW silages had higher concentrations of DM ( $\mathrm{p}=0.016 ; 28.4 \%$ vs $26.7 \%$ ), $\mathrm{EE}$ ( $\mathrm{p}=0.030 ; 3.86 \%$ vs $3.78 \%)$, crude ash ( $<<0.001 ; 6.85$ vs 5.96$)$, IVDMD ( $<<0.001$; $71.4 \%$ vs $64.3 \%$ ), and IVNDFD ( $\mathrm{p}=0.001 ; 50.2 \%$ vs $45.2 \%$ ) than PI silages (Table 2). However, PI silages had higher concentrations of $\mathrm{CP}(\mathrm{p}<0.001 ; 9.61 \%$ vs $8.62 \%)$ and $\mathrm{ADF}(\mathrm{p}=$ $0.009 ; 27.1 \%$ vs $25.9 \%$ ) than KW silages. The NDF concentration was not affected ( $\mathrm{p}>0.05)$ by corn hybrids. However, LP silages had higher CP ( $\mathrm{p}=0.039 ; 9.24 \%$ vs $8.99 \%)$, but lower EE concentrations ( $\mathrm{p}<0.001 ; 3.75 \%$ vs $3.89 \%$ ) than $\mathrm{LB}$ silages. The interactions between hybrid and inoculant only affected EE $(p=0.002)$ and NDF $(p=0.009)$ concentrations.

\section{Fermentation indices of corn silage}

The KW silages had lower concentrations of ammonia- $\mathrm{N}(\mathrm{p}$ $=0.001 ; 0.09 \%$ vs $0.11 \%)$ and acetate $(\mathrm{p}=0.025 ; 0.88 \%$ vs $1.00 \%)$ than PI silages (Table 3). LP silages had higher lactate concentration ( $\mathrm{p}=0.002 ; 3.12 \%$ vs $2.07 \%)$ and lactate to acetate ratio $(\mathrm{p}=0.002 ; 4.18$ vs 2.11$)$, but lower acetate concentration ( $\mathrm{p}<$ $0.001 ; 0.76 \%$ vs $1.12 \%)$ than LB silages. The interaction between hybrid and inoculant only affected $(\mathrm{p}=0.008)$ acetate concentration.

Table 2. Effects of inoculant application on chemical composition and in vitro digestibility of corn silages ensiled for 100 days (\%, DM)

\begin{tabular}{|c|c|c|c|c|c|c|c|c|}
\hline \multirow{2}{*}{ Items } & \multicolumn{2}{|c|}{$K W^{1)}$} & \multicolumn{2}{|c|}{$\mathrm{PI}^{1)}$} & \multirow{2}{*}{ SEM } & \multicolumn{3}{|c|}{ Contrast $^{2)}$} \\
\hline & LP & LB & LP & LB & & HY & INO & HYXINO \\
\hline Dry matter & 28.3 & 28.5 & 26.3 & 27.1 & 0.948 & 0.016 & 0.406 & 0.570 \\
\hline Crude protein & 8.81 & 8.43 & 9.67 & 9.55 & 0.175 & $<0.001$ & 0.039 & 0.228 \\
\hline Ether extract & 3.80 & 3.91 & 3.69 & 3.86 & 0.030 & 0.030 & $<0.001$ & 0.002 \\
\hline Crude ash & 6.94 & 6.75 & 5.93 & 5.98 & 0.104 & $<0.001$ & 0.304 & 0.164 \\
\hline NDF & 47.4 & 46.5 & 46.5 & 48.0 & 0.555 & 0.499 & 0.379 & 0.009 \\
\hline ADF & 25.9 & 25.8 & 26.5 & 27.6 & 0.787 & 0.009 & 0.151 & 0.112 \\
\hline IVDMD & 71.4 & 71.3 & 64.3 & 64.2 & 0.665 & $<0.001$ & 0.842 & 1.000 \\
\hline IVNDFD & 50.2 & 50.1 & 45.4 & 44.9 & 0.716 & 0.001 & 0.585 & 0.647 \\
\hline
\end{tabular}

DM, dry matter; SEM, standard error of mean; NDF, neutral detergent fiber; ADF, acid detergent fiber; IVDMD, in vitro DM digestibility; IVNDFD, in vitro NDF digestibility.

${ }^{1)} \mathrm{KW}$, Kwangpyeongok hybrid; PI, Pioneer 1543 hybrid; LP, corn silage inoculated with Lactobacillus plantarum; LB, corn silage inoculated with Lactobacillus buchneri.

${ }^{2)} \mathrm{HY}$, hybrid effect; INO, inoculant effect; $\mathrm{HY} \times \mathrm{INO}$, interaction between hybrid and inoculant. 
Table 3. Effects of inoculant application on fermentation indices of corn silages ensiled for 100 days

\begin{tabular}{|c|c|c|c|c|c|c|c|c|}
\hline \multirow{2}{*}{ Items } & \multicolumn{2}{|c|}{$\mathrm{KW}^{1)}$} & \multicolumn{2}{|c|}{$\mathbf{P I}^{1)}$} & \multirow{2}{*}{ SEM } & \multicolumn{3}{|c|}{ Contrast $^{2)}$} \\
\hline & LP & LB & LP & LB & & HY & INO & HYXINO \\
\hline $\mathrm{pH}$ & 3.85 & 3.88 & 3.88 & 3.93 & 0.075 & 0.331 & 0.404 & 0.853 \\
\hline Ammonia-N (\%) & 0.09 & 0.08 & 0.11 & 0.11 & 0.008 & 0.001 & 0.440 & 0.953 \\
\hline Lactate (\%) & 3.14 & 2.13 & 3.09 & 2.01 & 0.213 & 0.623 & 0.002 & 0.828 \\
\hline Acetate (\%) & 0.78 & 0.98 & 0.74 & 1.25 & 0.062 & 0.025 & $<0.001$ & 0.008 \\
\hline Propionate (\%) & 0.15 & 0.14 & 0.15 & 0.19 & 0.033 & 0.371 & 0.479 & 0.244 \\
\hline Butyrate (\%) & ND & ND & ND & ND & - & - & - & - \\
\hline La:Ac & 4.03 & 2.17 & 4.18 & 1.61 & 0.319 & 0.227 & 0.002 & 0.353 \\
\hline
\end{tabular}

SEM, standard error of mean; La:Ac, lactate to acetate ratio; ND, not detected.

1) KW, Kwangpyeongok hybrid; PI, Pioneer 1543 hybrid; LP, corn silage inoculated with Lactobacillus plantarum; LB, corn silage inoculated with Lactobacillus buchneri.

2) $H Y$, hybrid effect; INO, inoculant effect; $H Y \times I N O$, interaction between hybrid and inoculant.

Aerobic stability and microbial count of corn silage Aerobic stability of corn silage was higher in KW than in PI silages ( $\mathrm{p}<0.001 ; 29.2$ vs 13.4$)$, but not affected $(\mathrm{p}>0.05)$ by inoculant (Table 4). The interaction effect among hybrid and inoculant was detected in aerobic stability $(p=0.006)$. Silages inoculated with LP had higher LAB count ( $\mathrm{p}=0.002 ; 6.15$ vs $4.50 \log 10 \mathrm{cfu} / \mathrm{g})$ and yeast count $(\mathrm{p}=0.018 ; 6.08$ vs $5.21 \log 10$ $\mathrm{cfu} / \mathrm{g}$ ) than LB. The mold count was not detected in all silages. The interaction between hybrid and inoculant affected $(\mathrm{p}=$ $0.016)$ aerobic stability and $\mathrm{LAB}(\mathrm{p}=0.048)$.

\section{Temperature change of corn silage during aerobic} exposure

A change of temperature in corn silages during aerobic exposure is shown in Figure 1. The KW silages produced lower $(\mathrm{p}<0.05)$ temperature than PI silages during the observation. However, it was not affected ( $\mathrm{p}>0.05)$ by inoculant. The temperatures of PI silage applied LP inoculant were highest $(\mathrm{p}<$ 0.05 ) at $1,2,4,8,10,15,20$, and $30 \mathrm{~h}$ of aerobic exposure compared to the other silages. The time when silage temperature was $2^{\circ} \mathrm{Chigher}$ than the ambient temperature, were in the order of PI silage with LP inoculant (10.3 h), PI silage with LB inoculant (15.0 h), KW silage with LB inoculant (21.9 h), and KW silage with LP inoculant (29.5 h).

\section{Microbial change of corn silage during aerobic}

\section{exposure}

The counts of LAB, yeast, and mold in corn silage during aerobic exposure are presented in Figure 2. The growth of microbes was not affected ( $p>0.05)$ by corn hybrid and inoculant, except LAB that was higher in LP than in LB inoculant applications $(\mathrm{p}=0.039)$. The LAB, yeast, and mold counts were gradually increased by 4 days of aerobic exposure, after then stable by 8 days. Among the treatments, the LAB count was highest $(\mathrm{p}<0.05)$ in PI silage with LP inoculant by 4 days of aerobic exposure. The yeast count was lowest $(\mathrm{p}<0.05)$ in $\mathrm{KW}$ silage with LB inoculant by 3 days of aerobic exposure, and in both hybrid silages with LB inoculant at 4 days. The mold count was lowest $(\mathrm{p}<0.05)$ in KW silage with both inoculants at 1 day, and in KW silage with LB inoculant at 2 and 3 days.

\section{DISCUSSION}

The chemical compositions of KW and PI hybrids were in the expected range for corn grown in South Korea $[9,10,24,25]$. In general, the differences of silage chemical compositions among hybrids are caused by those of forages $[12,13]$. In the present study, the results of higher EE and crude ash concentrations in KW silage, but lower $\mathrm{CP}$ and $\mathrm{ADF}$ concentrations than PI silages might be due to those compositions of corn forages. On the other side, a higher $\mathrm{CP}$ concentration by LP than LB silages indicated lower proteolysis in homo fermen-

Table 4. Effects of inoculant application on aerobic stability and microbial counts of corn silages ensiled for 100 days

\begin{tabular}{|c|c|c|c|c|c|c|c|c|}
\hline \multirow{2}{*}{ Items } & \multicolumn{2}{|c|}{$K W^{1)}$} & \multicolumn{2}{|c|}{$P I^{1)}$} & \multirow{2}{*}{ SEM } & \multicolumn{3}{|c|}{ (ontrast $^{2)}$} \\
\hline & LP & LB & LP & LB & & HY & INO & HYXINO \\
\hline Aerobic stability (h) & 32.8 & 25.5 & 8.08 & 18.7 & 3.302 & $<0.001$ & 0.468 & 0.006 \\
\hline LAB (log10 cfu/g) & 6.04 & 5.00 & 6.25 & 4.00 & 0.301 & 0.136 & 0.002 & 0.048 \\
\hline Yeast (log 10 cfu/g) & 6.15 & 5.17 & 6.01 & 5.25 & 0.327 & 0.987 & 0.018 & 0.987 \\
\hline Mold (log10 cfu/g) & ND & ND & ND & ND & - & - & - & - \\
\hline
\end{tabular}

LAB, lactic acid bacteria; SEM, standard error of mean; cfu, colony forming unit; ND, not detected.

1) KW, Kwangpyeongok hybrid; PI, Pioneer 1543 hybrid; LP, corn silage inoculated with Lactobacillus plantarum; LB, corn silage inoculated with Lactobacillus buchneri.

2) $\mathrm{HY}$, hybrid effect; INO, inoculant effect; $\mathrm{HY} \times \mathrm{INO}$, interaction between hybrid and inoculant. 


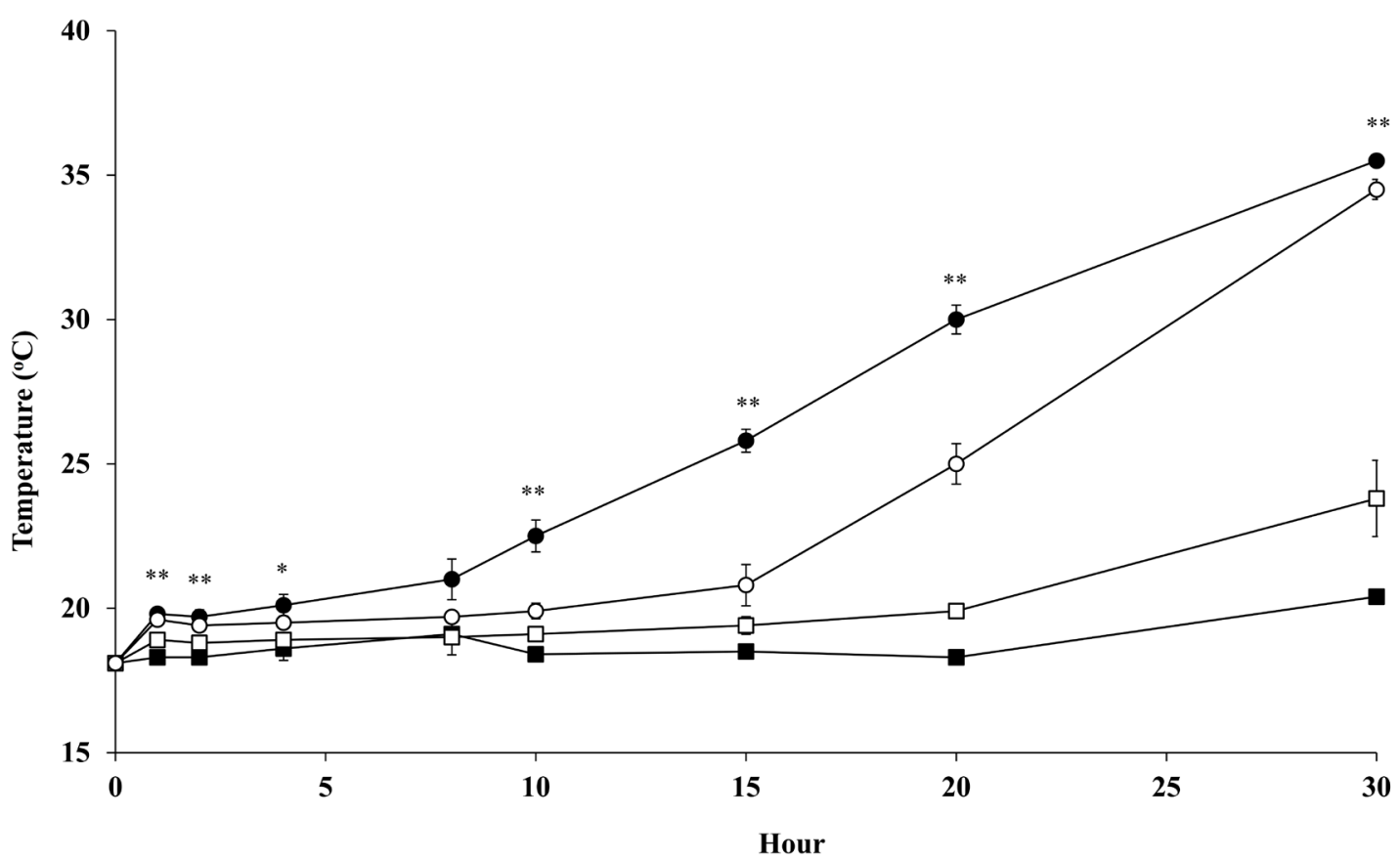

Figure 1. Effects of inoculant application on temperature of corn silage during aerobic exposure. Kwangpyeongok corn silage inoculated with Lactobacillus plantarum (or Lactobacillus buchneri ( $\square)$; Pioneer 1543 corn silage inoculated with Lactobacillus plantarum (•) or Lactobacillus buchneri (o). The respective significance levels of hybrid, inoculant, hybridxinoculant, and SEM for temperature are $p<0.001, p=0.087, p=0.319$, and SEM $=3.783$. Values differ among groups within same hour * $p<0.05$ and ${ }^{* *} p<0.01$. SEM, standard error of mean.

tative LAB [26]. The reason for higher EE concentration in LP than LB silages was not clear, but it could be due to higher total organic acid concentration in LP silages, which caused a lower nutrient loss, including $\mathrm{EE}$ concentration during fermentation [6]. The NDF concentration was affected by interaction among hybrid and inoculant that presented higher concentration in PI silage, but lower in KW silage when using LB inoculant in both hybrids. The effects of inoculant on chemical compositions of silage can vary depending hybrids [27]. The higher IVDMD and IVNDFD of KW than PI silages could be influenced by lower ADF concentration in KW compared to PI silages [28].

In fermentation indices, $\mathrm{pH}$ of all silages was below 4.0 which could be an indicator of enough acidification to inhibit the growth of undesirable microbes $[7,15,27]$. In the present study, the absence of butyrate and mold in all silages might be caused by rapid acidification and low $\mathrm{pH}$ in silage (Tables 3, 4). Ammonia- $\mathrm{N}$ in silage is a by-product of $\mathrm{CP}$ degradation during ensiling and its concentration could be affected by $\mathrm{CP}$ concentration of forages [6,27]. The higher ammonia- $\mathrm{N}$ in PI than in KW silages might be caused by the higher $\mathrm{CP}$ concentration in PI than in KW corn forages (10.40\% vs $9.65 \%)$. The differences of chemical composition among KW and PI forages caused LB inoculant to produce a different response in producing organic acids. According to McDonald et al [6], the WSC concentration and buffer capacity of forage influences the LAB development during ensiling. The previous studies also reported that organic acid profiles of silage could be influenced by interaction effect between hybrid and inoculant that also caused variation in results depending on types of inoculant and hybrid [17,27]. In the present study, LP as homo fermentative inoculant increased lactate concentration in both hybrids, whereas LB as hetero fermentative inoculant increased acetate concentration more effectively in PI silage than in KW silage (hybrid and inoculant interaction). These results of organic acid concentrations supported lactate to acetate ratio in the present study, which was higher ratio in LP and KW silages than in LB and PI silages, respectively.

According to previous study [14], inoculation of silage with homo fermentative LAB had beneficial effects in promoting the $\mathrm{LAB}$ growth, which was similar result with $\mathrm{LAB}$ count in the present study. Applied LB inoculant in the present study decreased the growth of yeast more effectively than LP due to higher acetate production (Table 3). Acetate has a role as antimicrobial compound against the undesirable microbes [29].

Application of hetero fermentative LAB increased aerobic stability of silage because it increases acetate concentration during ensiling $[15,16,29]$. In the present study, applied LB inoculant only increased aerobic stability in PI silage without any improvement in KW silage, which was similar to results in a previous study [13]. In aerobic stability of KW silages, the reason for no effect among inoculants could be supported partially by the similar acetate concentrations of LP and LB inoculants $(0.78 \%$ vs $0.98 \%)$. Temperatures of all silages were 

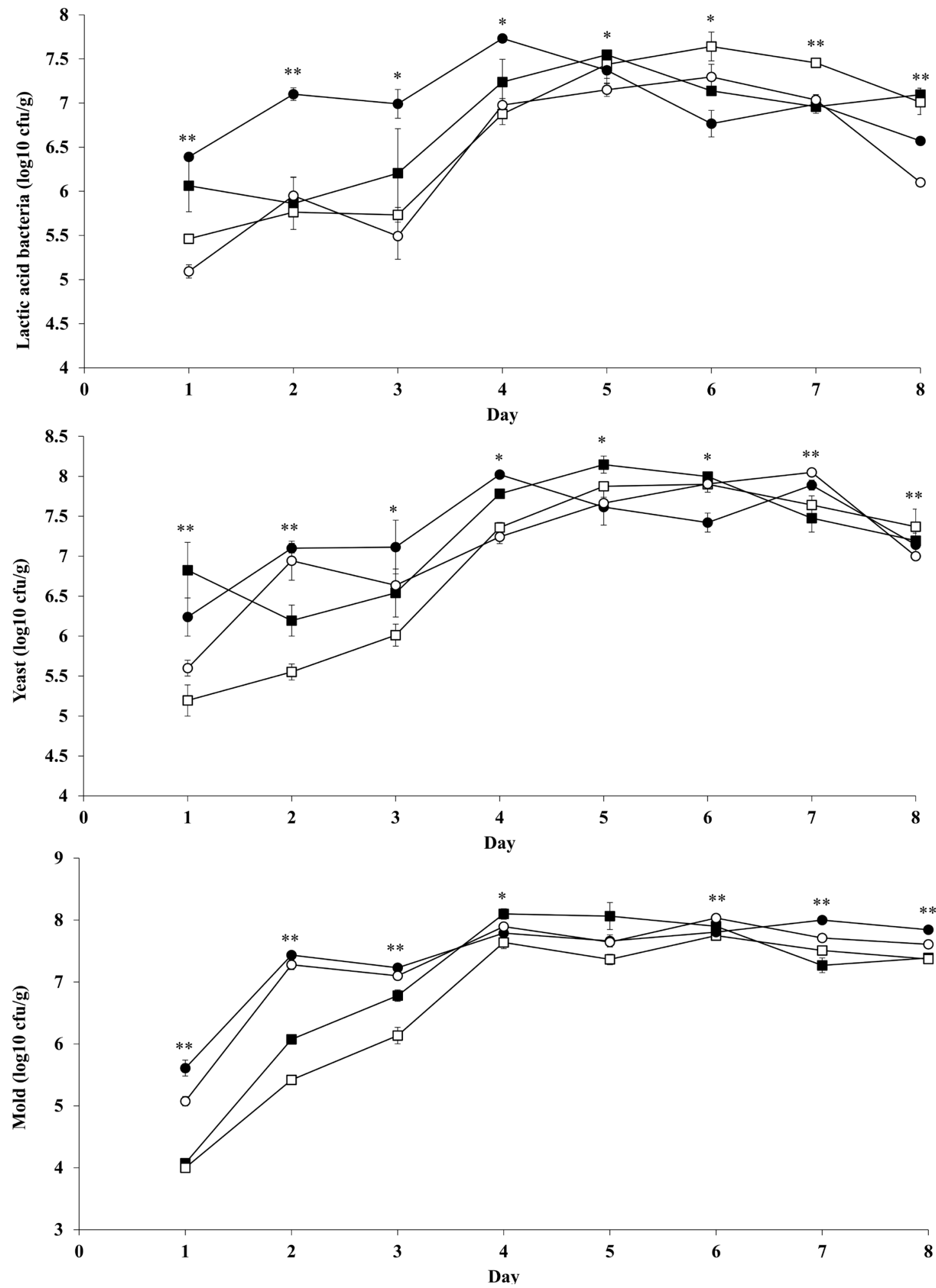

Figure 2. Effects of inoculant application on lactic acid bacteria, yeast, and mold counts of corn silages during aerobic exposure. Kwangpyeongok corn silage inoculated

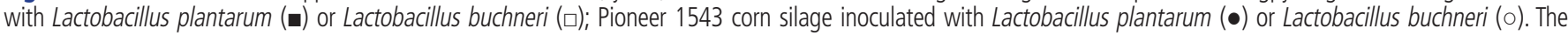
respective significance levels of hybrid, inoculant, hybridxinoculant, and SEM for lactic acid bacteria, yeast, and mold are $p=0.856, p=0.039, p=0.126$, and SEM $=$ $0.809 ; p=0.388, p=0.099, p=0.842$, and SEM $=0.879 ; p=0.063, p=0.493, p=0.598$, and $S E M=1.072$, respectively. Values differ between groups within same hour * $p<0.05$ and ** $p<0.01$. SEM, standard error of mean. 
gradually increased during the aerobic exposure under room temperature $\left(20^{\circ} \mathrm{C}\right)$, and $\mathrm{KW}$ silages had 2 times higher aerobic stability than PI silages. This might be caused by the hybrid effect [13]. Even though PI silages had slightly higher acetate concentration $(1.00 \%$ vs $0.88 \%)$ than KW silages, it showed higher population of mold by 3 days of aerobic exposure (Figure 2). This might contribute to a decrease aerobic stability. The shelf life of silage is usually estimated by aerobic stability [6]. Determination of aerobic stability should consider not only a change of temperature but also microbial growth during aerobic conditions. In the present study, LAB count after silo opened was influenced by interaction effect among hybrid and inoculant that agreed with previous study [27]. And during aerobic exposure, LAB still could grow 4-5 days because several strains were classified as aerotolerant anaerobes, such as L. plantarum, Leuconostoc mesenteriodes, and Streptococcus lactis [30]. Also, anaerobic condition in the bottom of silage container still allowed LAB to grow. This principle could be applied to bunker silo that represented the front side of silo in aerobic condition, but the end side of silo in anaerobic condition [7]. The growth of LAB did not inhibit yeast and mold after silo open in the present study. In yeast count, KW silage with LP inoculant showed the similar count at day 0 (6.15 log10 $\mathrm{cfu} / \mathrm{g})$ and $2(6.19 \log 10 \mathrm{cfu} / \mathrm{g})$ of aerobic exposure. Moreover, KW silage with LB inoculant still presented the yeast count at $5.5 \log 10 \mathrm{cfu} / \mathrm{g}$ during 2 days of aerobic exposure. It indicated that yeast count in KW silages with both inoculants was relatively stable or slow growth for 2 days, even though its temperature was $2^{\circ} \mathrm{C}$ higher than ambient. LP and LB inoculants presented a similar effect on yeast growth in KW silage due to both inoculants having a similar concentration of acetate (Table 3). In PI silages, both inoculant treatments showed a similar count at day $0(5.63 \log 10 \mathrm{cfu} / \mathrm{g})$ and $1(5.91 \log 10 \mathrm{cfu} / \mathrm{g})$ of aerobic exposure. It also indicated the yeast count in PI silage was relatively stable or slow growth until day 1 , even though the temperature was reported $16^{\circ} \mathrm{C}$ higher than ambient. The growth of yeast stimulated the mold that might have direct effect on increases of temperature in the present study. In 1 day of aerobic exposure, mold was detected and generally the aerobic stability finished in all treatments. This might indicate that mold was the main contributor to increases of silage temperature in the present study. Previous study reported that yeast and mold utilized remaining nutrients such as lactate and WSC to grow during aerobic exposure and decrease aerobic stability of silage as a response of temperature increases $[15,29]$. However, the present study indicated that increase of silage temperature was mainly influenced by mold, while the yeast contribution was to stimulate the mold growth. A high acetate concentration in LB silages resulted in a lower yeast count than LP silages, which was similar to a previous study [15].

\section{CONCLUSION}

During aerobic exposure, $\mathrm{LAB}$ could still grow for 4 to 5 days of aerobic condition, but it did not inhibit the growth of undesirable microbes. The yeast stimulated the mold growth in the present study. Changes of silage temperature during aerobic exposure seems mainly due to mold growth. Inoculation of silages with LP as homo fermentative inoculant improved the fermentation indices in both hybrids, while inoculation with LB as hetero fermentative inoculant only enhanced aerobic stability of PI hybrid.

\section{CONFLICT OF INTEREST}

We certify that there is no conflict of interest with any financial organization regarding the material discussed in the manuscript.

\section{ACKNOWLEDGMENTS}

This research was performed with the support of "Cooperative Research Program for Agriculture Science \& Technology Development (Project No. PJ013869022018)" Rural Development Administration, South Korea.

\section{REFERENCES}

1. Allen MS, Coors JG, Roth GW. Corn silage. In: Buxton DR, Muck RE, Harrison JH, editors. Silage science and technology. Madison, WI, USA: American Society of Agronomy; 2003. p. 547-608.

2. Garon D, Richard E, Sage L, et al. Mycoflora and multimycotoxin detection in corn silage: experimental study. J Agric Food Chem 2006;54:3479-84.

3. Richard E, Heutte N, Sage L, et al. Toxigenic fungi and mycotoxins in mature corn silage. Food Chem Toxicol 2007;45:24205.

4. Wilkinson JM, Davies DR. The aerobic stability of silage: key findings and recent developments. Grass Forage Sci 2013;68:119.

5. Pahlow G, Muck RE, Driehuis F, Oude Elferink SJWH, Spoelstra SF. Microbiology of ensiling. In: Buxton DR, Muck RE, Harrison $\mathrm{JH}$, editors. Silage science and technology. Madison, WI, USA: American Society of Agronomy; 2003. p. 31-93.

6. McDonald P, Henderson AR, Heron SJE. The biochemistry of silage, 2nd ed. Bucks, UK: Chalcombe Publ; 1991.

7. Arriola KG, Kim SC, Adesogan AT. Effect of applying inoculants with heterolactic or homolactic and heterolactic bacteria on the fermentation and quality of corn silage. J Dairy Sci 2011; 94:1511-6.

8. Ashbell G, Weinberg ZG, Azrieli A, Hen Y, Horev B. A simple system to study the aerobic deterioration of silages. Can Agric 
Eng 1991;33:391-3.

9. Moon HG, Son BY, Cha SW, et al. A new single cross maize hybrid for silage "Kwangpyeongok". Korean J Breed Sci 2001; 33:350-1.

10. Buriro M, Bhutto TA, Gandahi AW, Kumbhar IA, Shar MU. Effect of sowing dates on growth, yield, and grain quality of hybrid maize. J Basic Appl Sci 2015;11:553-8.

11. Andrae JG, Hunt CW, Pritchard GT, et al. Effect of hybrid, maturity, and mechanical processing of corn silage on intake and digestibility by beef cattle. J Anim Sci 2001;79:2268-75.

12. Johnson LM, Harrison JH, Davidson D, et al. Corn silage management II: Effects of hybrid, maturity, and mechanical processing on digestion and energy content. J Dairy Sci 2002;85: 2913-27.

13. Kang TW, Adesogan AT, Kim SC, Lee SS. Effects of an esteraseproducing inoculant on fermentation, aerobic stability, and neutral detergent fiber digestibility of corn silage. J Dairy Sci 2009;92:732-8.

14. Cai Y, Benno Y, Ogawa M, Kumai S. Effect of applying lactic acid bacteria isolated from forage crops on fermentation characteristics and aerobic deterioration of silage. J Dairy Sci 1999; 82:520-6.

15. Ranjit NK, Kung L Jr. The effect of Lactobacillus buchneri, Lactobacillus plantarum, or a chemical preservative on the fermentation and aerobic stability of corn silage. J Dairy Sci 2000;83: 526-35.

16. Filya I, Sucu E. The effect of bacterial inoculants and a chemical preservative on the fermentation and aerobic stability of wholecrop cereal silages. Asian-Australas J Anim Sci 2007;20:37884.

17. Johnson LM, Harrison JH, Davidson D, Mahanna WC, Shinners K. Corn silage management: effects of hybrid, maturity, inoculation, and mechanical processing on fermentation characteristics. J Dairy Sci 2003;86:287-308.

18. AOAC. Official methods of analysis. 15th edn. Association of Official Analytical Chemists, Arlington, VA, USA: AOAC International; 1995.

19. Van Soest PJ, Robertson JB, Lewis BA. Methods for dietary fiber, neutral detergent fiber, and nonstarch polysaccharides in relation to animal nutrition. J Dairy Sci 1991;74:3583-97.

20. Tilley JMA, Terry RA. A two-stage technique for the in vitro digestion of forage crops. J Br Grassl Soc 1963;18:104-11.

21. Chaney AL, Marbach EP. Modified reagents for determination of urea and ammonia. Clin Chem 1962;8:130-2.

22. Muck RE, Dickerson JT. Storage temperature effects on proteolysis in alfalfa silage. Trans ASASE 1988;31:1005-9.

23.SAS Institute Inc. SAS/STAT user's guide: Version 9. Cary, NC, USA: SAS Institute Inc.; 2002.

24. Son BY, Kim JT, Song SY, et al. Comparison of yield and forage quality of silage corns at different planting dates. J Kor Grassl Forage Sci 2009;29:179-86.

25.Lee SM. Effects of ridging times on agronomic characteristics, yield and feed value of corn hybrid for silage in paddy field cultivation. J Kor Grassl Forage Sci 2012;32:265-74.

26. Driehuis F, Oude Elferink SJWH, Van Wikselaar PG. Fermentation characteristics and aerobic stability of grass silage inoculated with Lactobacillus buchneri, with or without homofermentative lactic acid bacteria. Grass Forage Sci 2001;56:33043.

27. Kim DH, Amanullah SM, Lee HY, et al. Effects of hybrid and bacterial inoculation on fermentation quality and fatty acid profile of barley silage. Anim Sci J 2018;89:140-8.

28. Dado RG, Allen MS. Intake limitations, feeding behavior, and rumen function of cows challenged with rumen fill from dietary fiber or inert bulk. J Dairy Sci 1995;78:118-33.

29. Danner H, Holzer M, Mayrhuber E, Braun R. Acetic acid increases stability of silage under aerobic conditions. Appl Environ Microbiol 2003;69:562-7.

30. Condon S. Responses of lactic acid bacteria to oxygen. FEMS Microbiol Lett 1987;46:269-80. 